\title{
Impact of nitric oxide precursor L-arginine on oxidative stress against typhoid
}

\author{
Haque SS \\ Department of Clinical Biochemistry, Indira Gandhi Institute of Medical Sciences Patna, India. \\ sshaq2002@yahoo.co.in
}

\begin{abstract}
Objectives: Typhoid fever is a global health problem caused by Salmonella. Salmonellae are gramnegative, flagellate, nonsporulating, facultative anaerobic bacilli that ferment glucose, reduce nitrate to nitrite, and synthesize peritrichous flagella when motile. Nowadays, most of the drugs are resistant, the fact of which compels the search for formulated drugs. Nitric oxide (NO) and its congeners react with different compounds or radicals probably mediating the broad-spectrum antimicrobial activity of reactive nitrogen species (RNS) as well as reactive oxygen species (ROS) against diverse microorganisms. Exogenous administration of L-arginine results in increased NO production. The formulation of NO precursors, (i.e. of $L$-arginine and ciprofloxacin) is used against experimentally induced salmonellosis. Lipid hydroperoxide can be decomposed to produce alkoxy and peroxy radicals which eventually yield numerous carbonyl products such as malondialdehyde (MDA). Material and methods: Estimation of lipid peroxidation (LPO) was done by modified method of Utley et al (1967). Results and discussion: Infection with S. typhimurium significantly induced lipid peroxidation on days 8 and 11 as indicated by enhancement of MDA levels compared to the control mice (20\% and $9.52 \%)$ (Tab. 1, Fig. 2 , Ref. 20). Full Text in PDF www.elis.sk.

Key words: nitric oxide, lipid peroxidation.
\end{abstract}

Typhoid fever (TF) is an important health problem in many developing countries, causing more than 600,000 deaths annually in the world. Infection of mice with Salmonella typhimurium gives rise to a disease similar to human typhoid fever caused by S. typhi (1). Salmonella can replicate within macrophages and this property is essential for its ability to cause systemic infection (2). NO is a diffusible free-radical effector molecule in diverse biological

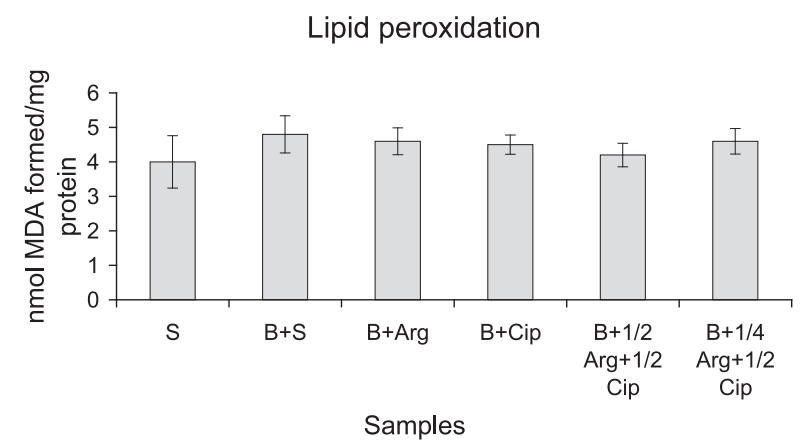

Fig. 1. Hepatic malonadialdehyde level measured in mice: drugs were given and study was made on day 8 . $S=S$ aline, $B+S=S$. typhimurium + Saline, $\mathrm{B}+\mathrm{Arg}=S$. typhimurium $+1000 \mathrm{mg}$ per $\mathrm{kg} \mathrm{b}$. wt L-Arginine, B+Cip=S. typhimurium $+400 \mathrm{mg}$ per $\mathrm{kg} \mathrm{b}$. wt Ciprofloxacin, $\mathrm{B}+1 / 2 \mathrm{Arg}+1 / 2 \mathrm{Cip}=$ S. typhimurium $+500 \mathrm{mg}$ per $\mathrm{kg} \mathrm{b}$. wt Arginine +200 mg per $\mathrm{kg} \mathrm{b}$. wt ciprofloxacin, $\mathrm{B}+1 / 4 \mathrm{Arg}+1 / 2 \mathrm{Cip}=S$. typhimurium +250 mg per kg b. wt Arginine+200mg per kg b. wt Ciprofloxacin.

Department of Clinical Biochemistry, Indira Gandhi Institute of Medical Sciences Patna, India

Address for correspondence: S.S. Haque, MD, Department of Clinical Biochemistry, Indira Gandhi Institute of Medical Sciences, Patna-14, India.

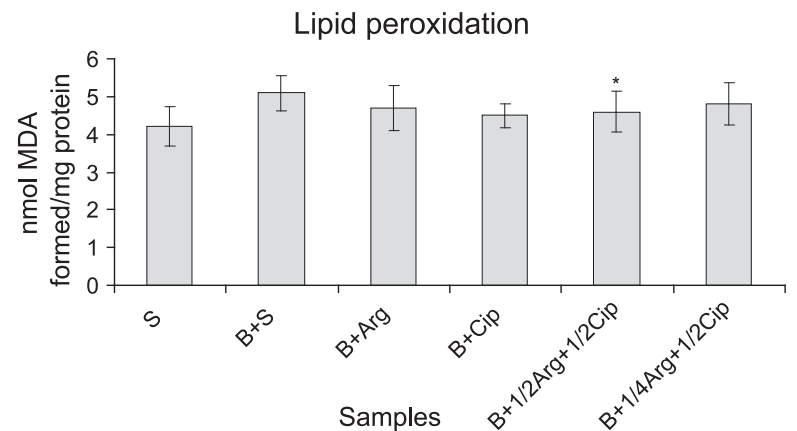

Fig. 2. Hepatic malonadialdehyde level measured in mice: drugs were given and study was made on day 11 . $S=S$ Saline, $B+S=S$. typhimurium + Saline, $\mathrm{B}+\mathrm{Arg}=S$. typhimurium $+1000 \mathrm{mg}$ per $\mathrm{kg} \mathrm{b}$. wt L-Arginine, B+Cip=S. typhimurium $+400 \mathrm{mg}$ per kg b. wt Ciprofloxacin,

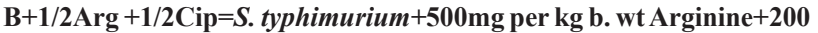
mg per kg b. wt ciprofloxacin, $\mathrm{B}+1 / 4 \mathrm{Arg}+1 / 2 \mathrm{Cip}=S$. typhimurium +250 mg per kg b. wt Arginine+200mg per kg b. wt Ciprofloxacin.

systems and an important component of host innate immunity. As such it plays an important role of an antimicrobial agent effective against intracellular pathogens (3). Reactive oxygen species such as superoxide anions, hydroxyl radical, and nitric oxide inactivate enzymes and damage important cellular components causing tissue injury through covalent binding and lipid peroxidation $(4,5)$. Nitric oxide is known to react with superoxide radical, forming peroxynitrite, an even more potent oxidizing agent (6). Peroxynitrite can react directly with sulfhydryl residues in cell membranes leading to lipid peroxidation as well as with DNA resulting in cytotoxicity (7). Lipid hydroperoxide can be decomposed to pro- 
duce alkoxy and peroxy radicals which eventually yield numerous carbonyl products such as malondialdehyde (MDA). The carbonyl products are responsible for DNA damage, generation of cancer and aging-related diseases (8). Thus the decrease in MDA level in formulated drugs indicates the antioxidant role of the drugs (Figs 1 and 2). The aim of this work was to establish the role of $\mathrm{NO}$ as an antioxidant.

\section{Material and methods}

\section{Dose and dosage}

Animals

Swiss albino mice (25-30 g, 6-8 weeks old) were obtained from the central animal house of Hamdard University, New Delhi, India. The animals were kept in Poly-propylene cages in an air-conditioned room at $22{ }^{\circ} \mathrm{C} / 25^{\circ} \mathrm{C}$ and maintained on standard laboratory feed (Amrut Laboratory, rat and mice feed, Navmaharashtra Chakan Oil Mills Ltd, Pune) and water ad libitum. Before the experiments, the animals were allowed to acclimatize for one week under controlled light/dark cycle (14/10 h). The studies were conducted according to ethical guidelines of the "Committee for the Purpose of Control and Supervision of Experiments on Animals" (CPCSEA) on the use of animals for scientific research.

\section{Bacteria}

In this experiment only Salmonella typhimurium (wild) was used. The standard strain of this pathogen was obtained from the National Salmonella Phage Typing Centre, Lady Harding Medical College, New Delhi, India. This bacterial strain was further confirmed by the Department of Microbiology, Majeedia Hospital, New Delhi, India. The drug was administered orally and $S$. typhimurium intraperitoneally.

Animals were divided into six groups. Each group comprised of six animals. The study comprised of following treatment schedules (Tab. 1).

Effects of above drugs on mice infected with S. typhimurium were analyzed. Post-treatment of experimental animals with drugs was done at above dose orally while the first group was considered as control receiving only saline. The second group was considered as positive control challenged with a sublethal dose of $S$. typhimurium $\left(0.6 \mathrm{xLD}_{50}\right)$ along with saline. The third group was challenged with a sublethal dose of $S$. typhimurium and given only a full dose of ciprofloxacin. The fourth group was challenged with a sublethal dose of $S$. typhimurium and then treated with a full

\section{Tab. 1. Treatment schedule.}

\begin{tabular}{|c|c|}
\hline Groups & Treatments \\
\hline Group1 & Negative control (Normal Saline) \\
\hline Group2 & Positive control $\left(S\right.$. typhimurium $\left(0.6 \mathrm{xLD}_{50}\right)+$ Saline \\
\hline Group3 & S. typhimurium $\left(0.6 \times \mathrm{LD}_{50}\right)+$ Ciprofloxacin $(400 \mathrm{mg}$ per kg b.wt) \\
\hline Group4 & S. typhimurium $\left(0.6 \times \mathrm{xD}_{50}\right)+\operatorname{Arginine}(1000 \mathrm{mg}$ per kg b.wt $)$ \\
\hline Group5 & $\begin{array}{l}\text { S. typhimurium }\left(0.6 \times \mathrm{LD}_{50}\right)+\text { Arginine }(500 \mathrm{mg} \text { per } \mathrm{kg} \text { b.wt })+ \\
\text { Ciprofloxacin }(200 \mathrm{mg} \text { per } \mathrm{kg} \text { b.wt })\end{array}$ \\
\hline Group6 & $\begin{array}{l}\text { S. typhimurium }\left(0.6 \times \mathrm{LD}_{50}\right)+\text { Arginine }(250 \mathrm{mg} \text { per } \mathrm{kg} \text { b.wt })+ \\
\text { Ciprofloxacin }(200 \mathrm{mg} \text { per } \mathrm{kg} \text { b.wt })\end{array}$ \\
\hline
\end{tabular}

dose of Arginine only. In the fifth and sixth groups, animals were challenged with S. typhimurium and then half and one fourth of doses of Arginine, respectively, were administered along with a half dose of Ciprofloxacin.

\section{Estimation of lipid peroxidation (LPO)}

The modified method of Utley et al (1967) was used for the estimation of lipid peroxidation. Liver homogenate $(1.0 \mathrm{ml})$ was pipetted in a glass vial of $20 \mathrm{ml}$ and incubated at $37 \pm 1{ }^{\circ} \mathrm{C}$ in water bath shaker for 60 minutes at 120 up and down strokes. The other $1.0 \mathrm{ml}$ was pipetted in a centrifuge tube and placed at $0{ }^{\circ} \mathrm{C}$ and marked as 0 hour incubation. After one hour of incubation, $1.0 \mathrm{ml}$ of $5 \%$ TCA and $1.0 \mathrm{ml}$ of $0.67 \%$ TBA (Thiobarbituric acid) was added in both samples (i.e. $0^{\circ} \mathrm{C}$ and $37^{\circ} \mathrm{C}$ ). The reaction mixture from the vial was transferred to the tube and centrifuged at 1500 xrpm for 15 minutes. The supernatant was transferred to another tube and placed in a boiling water bath for 10 minutes. Thereafter, the test tubes were cooled and the absorbance of the color was read at $535 \mathrm{~nm}$. The formation of lipid peroxidation (LPO) was expressed as nmol of malondialdehyde (MDA) formed/hr/mg protein.

\section{Statistics}

Values are expressed as mean \pm SE. and compared with ANOVA for repeated measures. Statistical significance was set at $\mathrm{p}<$ 0.05 .

\section{Results}

The mice were challenged with a sublethal dose of $S$. $t y$ phimurium $\left(0.6 \times \mathrm{LD}_{50}\right)$ after seven days, the drugs were given as scheduled, and malonadialdehyde (MDA) production by TBA was measured as an indicator for LPO. The results have been summarized in Figures 1 and 2. The infection with S. typhimurium significantly induced lipid peroxidation on days 8 and 11 as indicated by enhancement of MDA levels compared to the control mice $(20 \%$ and $9.52 \%)$.

After treatment with L-Arginine, Ciprofloxacin and their combination, on day 8 , it was observed that the levels of LPO in mice were decreased by $4.16 \%, 6.25 \%, 12.5 \%$ and $4.16 \%$, similarly, the results on day 11 showed LPO levels decreased by $13.04 \%$, $13.04 \%, 26.08 \%$ and $17.39 \%$.

Thus, the treatment with L-Arginine, Ciprofloxacin and their combination partially protected the liver against the infectioninduced damage, and in this dose (B+1/2 Arg+1/2 Cip), some recovery was seen in case of lipid peroxidation in 11 days only.

\section{Discussion}

Lipid bilayer membranes define the extent of cells and organelles. The permeability characteristics of the bilayer allow the formation of gradients of metabolites and electrolytes concentrations to exist between intracellular and extracellular spaces. Any loss in membrane integrity due to lipid damage will rapidly dissipate these gradients and compromise the cellular functions. Lipid oxidation is a chain reaction. A single oxidative event can oxidize 
many lipid molecules. In the presence of iron or copper ions, the chain reaction can become a cascade and the oxidation process can rapidly become unstoppable $(9,10)$.

The mechanisms by which the initiation of lipid peroxidation occurs in vivo are not well defined but are likely to be a subset of mechanisms that have been carefully studied in vitro (11). Nitric oxide is not a strong oxidant and cannot extract bisallelic hydrogen from an unsaturated fatty acid to begin the peroxidation chain reaction (12). NO can both promote and inhibit $\mathrm{O}_{2}, \mathrm{H}_{2} \mathrm{O}_{2}$ and OONOdependent lipid peroxidation and yield novel nitrogen-containing derivatives of oxidized lipids (13). The rate of propagation of lipid peroxidation (LPO) depends on the steady state concentration of lipid peroxyl radicals. The rate constant for radical-radical reaction between $\mathrm{NO}$ and peroxyl radicals in aqueous solution has been determined to be $1-3 \times 10^{9}$ (14). However, several studies have suggested that $\mathrm{NO}$ is a potent inhibitor of the propagation reaction $(15,16,17,18)$.

In light of potent inhibitory effect of NO on lipid peroxidation, it is not certain that the lipid peroxidation chain reaction could ever proceed in the presence of physiological concentration of NO (19).

As observed in the present study, the increase in lipid peroxidation in S. typhimurium-infected mice indicates damage to the hepatic cells due to lipid peroxidation of hepatocytes membrane by generation of free radical derivatives (20). The observation of elevated levels of hepatic MDA in control mice in the present study is consistent with this hypothesis. Drugs showed an ability to prevent the $S$. typhimurium-induced enhancement of MDA content, suggesting that this combination $(\mathrm{B}+1 / 2$ 116. Arg $+1 / 2$ Cip) inhibits lipid peroxidation more as compared with others (Figs 1 and 2).

\section{References}

1. Darley-Usmar VM, Hogg N, O'Leary VJ, Wilson MT, Moncada S. The simultaneous generation of superoxide and nitric oxide can initiate lipid peroxidation in human low density lipoprotein. Free Radic Res Commun 1992; 17 (1): 9-20.

2. Fields PI, Swanson RV, Haidaris CG, Heffron F. Mutants of Salmonella typhimurium that cannot survive within the macrophage are avirulent. Proc Natl Acad Sci USA 1986; 83: 5189-5193.

3. Geesin JG, Gordon JS, Berg RA. Retinoids affect collagen synthesis through inhibition of ascorbate induced lipid peroxidation in cultured human dermal fibroblast. Arch Biochem Biphys 1990; 278: 352-355.
4. Goss SPA, Hogg N, Kalyanaraman B. The effect of nitric oxide release rates on the oxidation of human low density lipoprotein. J Biol Chem 1997; 272: 21 647-21 653 .

5. Hagerman AE, Riedl KM, Jones GA, Sovik KN, Ritchard NT, Hartzfeld PW. High molecular weight plant polyphenolics (tannins) as biological antioxidants. J Agric And Food Chem 1998; 46: 1887-1892.

6. Haque SS. Formulation of nitric oxide donors and antibiotic against typhoid. J Med Genet Genom 2011; 3 (3): 50-55.

7. Halliwell B, Gutteridge JM. Free radicals, lipid peroxidation, and cell damage. Lancet 1984; 10 (8411): 1095.

8. Hochstein P, Atallah H. The nature of oxidants and antioxidant systems in the inhibition of mutation and cancer. Mutat Res 1998 ; 202 : 363-375.

9. Ischiropoulos H, Zhu L, Beckman JS. Arch Biochem Biophys 1992; 298: 446-451.

10. Marx JL. Oxygen free radicals linked to many diseases. Science 1987; 235: 512-529.

11. Hogg N, Kalyanaraman B. Nitric oxide and lipid peroxidation. Biochim Biophys Acta1999; 1411: 378-384.

12. Hayashi K, Noguchi N, Niki E. Action of nitric oxide as an antioxidant against oxidation of soybean phosphatidyl-choline liposomal membranes. FEBS Lett 1995; 370: 37-40.

13. Hogg N, Darley-Usmar VM, Graham A, Moncada S. Peroxynitrite and atherosclerosis. Biochem Soc Trans 1993; 21: 358-362.

14. Marx JL. Oxygen free radicals linked to many diseases. Science 1987; 235: 512-529.

15. Padmaja, S, Huie RE. The reaction of nitric oxide with organic peroxyl radicals. Biochem Biophys Res Commun 1993; 195: 539-544.

16. Riemersma RA, Carruthers KF, Elton RA, Fox KA. Vitamin-C and the risk of acute myocardial infarction. Am J Clin Nutr 2000; 179: 1181-1186.

17. Rubbo H, Denacola A, Radi R. Peroxynitrite inactivates thiol-containing enzymes of Trypanosoma cruzi energetic metabolism and inhibits cell respiration. Arch Biochem Biophys 1994; 308: 96-102.

18. Rubbo H, Parthasarathy S, Barnes S, Kir M, Kalyanaraman B, Freeman BA. Nitric oxide inhibition of lipoxygenase-dependent liposome and low-density lipoprotein oxidation: termination of radical chain propagation reactions and formation of nitrogen-containing oxidized lipid derivatives. Arch Biochem Biophys 1995; 324: 15-25.

19. Recknagel RO, Glende EA Jr, Dolak JA, Waller RL. Mechanisms of carbon tetrachloride toxicity. Pharmacol Ther 1991; 43: 139-154.

20. Utley HC, Bernheim F, Hachstein P. Effect of sulfhydryl reagent on peroxidation in microsome. Arch Biochem Biophys 19667; 260: 521-531.

Received March 20, 2012. Accepted June 26, 2012. 